\title{
Climate change and the potential global distribution of Aedes aegypti: spatial modelling using geographical information system and CLIMEX
}

\author{
Hassan M. Khormi ${ }^{1,2}$, Lalit Kumar ${ }^{3}$ \\ ${ }^{1}$ KACST GIS Technology Innovation Centre, Umm Al-Qura University, P.O. Box 715, Makkah, 21955, Saudi \\ Arabia; ${ }^{2}$ Department of Geography, Umm Al-Qura University, P.O. Box 715, Makkah, 21955, Saudi Arabia; \\ ${ }^{3}$ Ecosystem Management, University of New England, Armidale NSW 2351 Australia
}

\begin{abstract}
We examined the potential added risk posed by global climate change on the dengue vector Aedes aegypti abundance using CLIMEX, a powerful tool for exploring the relationship between the fundamental and realised niche of any species. After calibrating the model using data from several knowledge domains, including geographical distribution records, we estimated potential distributions of the mosquito under current and future potential scenarios. The impact of climate change on its potential distribution was assessed with two global climate models, the CSIRO-Mk3.0 and the MIROC-H, run with two potential, future emission scenarios (A1B and A2) published by the Intergovernmental Panel on Climate Change. We compared today's climate situation with two arbitrarily chosen future time points (2030 and 2070) to see the impact on the worldwide distribution of $A$. aegypti. The model for the current global climate indicated favourable areas for the mosquito within its known distribution in tropical and subtropical areas. However, even if much of the tropics and subtropics will continue to be suitable, the climatically favourable areas for A. aegypti globally are projected to contract under the future scenarios produced by these models, while currently unfavourable areas, such as inland Australia, the Arabian Peninsula, southern Iran and some parts of North America may become climatically favourable for this mosquito species. The climate models for the Aedes dengue vector presented here should be useful for management purposes as they can be adapted for decision/making regarding allocation of resources for dengue risk toward areas where risk infection remains and away from areas where climatic suitability is likely to decrease in the future.
\end{abstract}

Keywords: Aedes aegypti, climate change, CLIMEX, dengue, geographical information system, infection.

\section{Introduction}

For thousands of years, climate has had wide-ranging impact on health. Scientific and media interests in the potential impact of climate change on health have increased recently (Hopp and Foley, 2001). For example, mosquito-borne diseases have received attention in terms of the association between climate variation and these diseases (Jackson, 1995; Martens et al., 1997). The World Health Organization (WHO) considers dengue fever one of the most important mosquito-borne diseases (Hopp and Foley, 2001; Hales et al., 2002; Khormi et al., 2011). Between 50 and 100 million dengue cases are currently recorded each year (WHO, 2013), especially in tropical and subtropical regions (Pinheiro and Chuit, 1998). Aedes aegypti is

\footnotetext{
Corresponding author:

Hassan M. Khormi

Department of Geography

Umm Al-Qura University

P.O. Box 715, Makkah 21955, Saudi Arabia

Tel. +966 2 527-0000; Fax +966 2527-0000

E-mail: hmkhormi@uqu.edu.sa
}

the main vector and it usually lives near human habitation areas (Rueda et al., 1990). Therefore, due to unavailability of effective vaccines and drug treatment for dengue (Khormi et al., 2011), management through control measures focussing on the vector, such as predicting potential sites, destroying breeding sites and application of insecticides, is the only way to minimise the impact of the disease.

Standing water and warm ambient temperatures are required for mosquitoes to breed and survive. Indeed, temperature is critical for adult feeding behaviour, larval development and the speed of virus replication, which makes transmission of the dengue virus strongly climate sensitive (Bliss and Gill, 1933; Chandler, 1945; Hales et al., 2002). Therefore, increasing global temperatures and other associated climate changes should affect and modify the geographical distribution and range of $A$. aegypti as pointed out by Hopp and Foley (2001) and Haines et al. (2006) and studies have already shown this effect (Martens et al., 1995, 1997; Jetten and Focks, 1997; Patz et al., 1998). Some concentrated on temperature-dependent calculations, such as adult mosquito survivorship and viral development 
(Khormi et al., 2013), while others have attempted to account for temperature-independent, epidemiological factors, such as the interaction between the infected mosquito and the susceptible human (Martens et al., 1997).

The United Nations Intergovernmental Panel on Climate Change (IPCC) has suggested the average global temperature may increase between $2{ }^{\circ} \mathrm{C}$ and $6{ }^{\circ} \mathrm{C}$ between 1990 and 2100 (IPCC, 2007). Relevant to mosquito-borne disease distribution, minimum temperatures are now increasing at a disproportionate rate compared to average and maximum temperatures (IPCC, 2007), a situation that may allow dengue and other mosquito-borne diseases to spread into regions previously free of these diseases. Changing conditions may exacerbate the situation by causing increased transmission in some endemic parts of the world (IPCC, 2007). For example, mosquitoes previously limited to $\leq 1,500 \mathrm{~m}$ above the mean level of the sea (MLS) in Colombia and Mexico have been found above 2,200 $\mathrm{m}$ above MLS, presumably due to the increase in temperature (Suarez and Nelson, 1981; Herrera-Basto et al., 1992; Hopp and Foley, 2001).

Most previous studies have focused on the sensitivity of dengue transmission determinants (Reiter, 1988; Hales et al., 1996; Patz et al., 1996) without providing quantitative assessments. Since the association between climate and dengue vector ecology is extremely important (Johansson et al., 2009), we decided to examine these issues that constitute the biophysical and socioeconomic drivers of global dengue patterns. To that end, we applied simulation analysis to project the impact of temperature, moisture, dryness and heat considering alterations in the potential effect of climate change on the distribution of A. aegypti. We felt that the CLIMEX modelling package (http://www.hearne.com.au/Software/CLIMEX/ Editions\#version_CLIMEX 3.0.2) would facilitate our approach, as it has been successfully used to estimate the potential of several different species with respect to spatio-temporal changes (Poutsma et al., 2008; Sutherst and Bourne, 2009; Chejara et al., 2010; Taylor et al., 2012). We focused on the main dengue vector, A. aegypti, because most major epidemics of the disease have occurred in areas where this mosquito is found (Gubler and Trent, 1994; Gubler and Clark, 1995; Gubler, 1998). A model of the climate responses of A. aegypti was developed based on the current, globally increasing trend of distribution. Using available, extensive distribution data to validate the model, we applied it to project possible future changes. Two global climate models (GCMs), CSIRO-
MK3.0 (CS) and MIROC-H (MR), were used to assess the impact of climate change on the potential distribution of $A$. aegypti at two arbitrarily chosen future time points, i.e. 2030 and 2070.

\section{Material and methods}

\section{Current global distribution of A. aegypti}

Information on the global distribution of A. aegypti was mainly collected from the Centers for Disease Control and Prevention (CDC, 2012) and the Center for International Earth Science Information Network (CIESIN, 2012) with input also from individual scientists (Gubler and Trent, 1994; Gubler and Clark, 1995; Gubler and Kuno, 1997; Moore and Mitchell, 1997; Gubler,1998a, 1998b, 2002，2003，2004; Moore, 1999; Lounibos, 2002; Gratz, 2004; Medlock et al., 2005). According to Gubler (1997), areas with dengue fever are infested by A. aegypti. It was difficult to find information for the time before 1960 as few control activities were specifically directed at dengue in the first half of the last century. During the Second World War, large-scale movements of susceptible populations led to a rise in dengue records (Gubler, 1997). Most of the tropical and subtropical regions are now infested by dengue and its vector with Latin America, Southeast Asia and the Pacific islands reporting most of the recent dengue cases (Rogers et al., 2006), while there is a dearth of information from sub-Saharan Africa due to the absence of local mosquito laboratory facilities there (Gubler, 1995). Fig. 1 shows the current, global distribution of the disease.

\section{Software used}

CLIMEX, an eco-climatic modelling package for exploring the relationship between the fundamental and realised niche of any species (Wharton and Kriticos, 2004; Kriticos et al., 2005), was used together with the eco-climatic index (EI). This annual index of climatic suitability is scaled from 0 to 100 and based on weekly calculations of the growth index $\left(\mathrm{GI}_{\mathrm{A}}\right)$ (in this case the mosquito population) and stress indexes (cold, wet, hot and dry). Any species can theoretically become established if the EI $>0$. However, if the value is close to 0 , the probability of conditions conducive to persistence in time and space is low, while it is very favourable at EI values of 30 . We used CLIMEX for Windows, version 3 to develop potential distribution models for A. aegypti under current and future climate scenarios. Based on the present and 


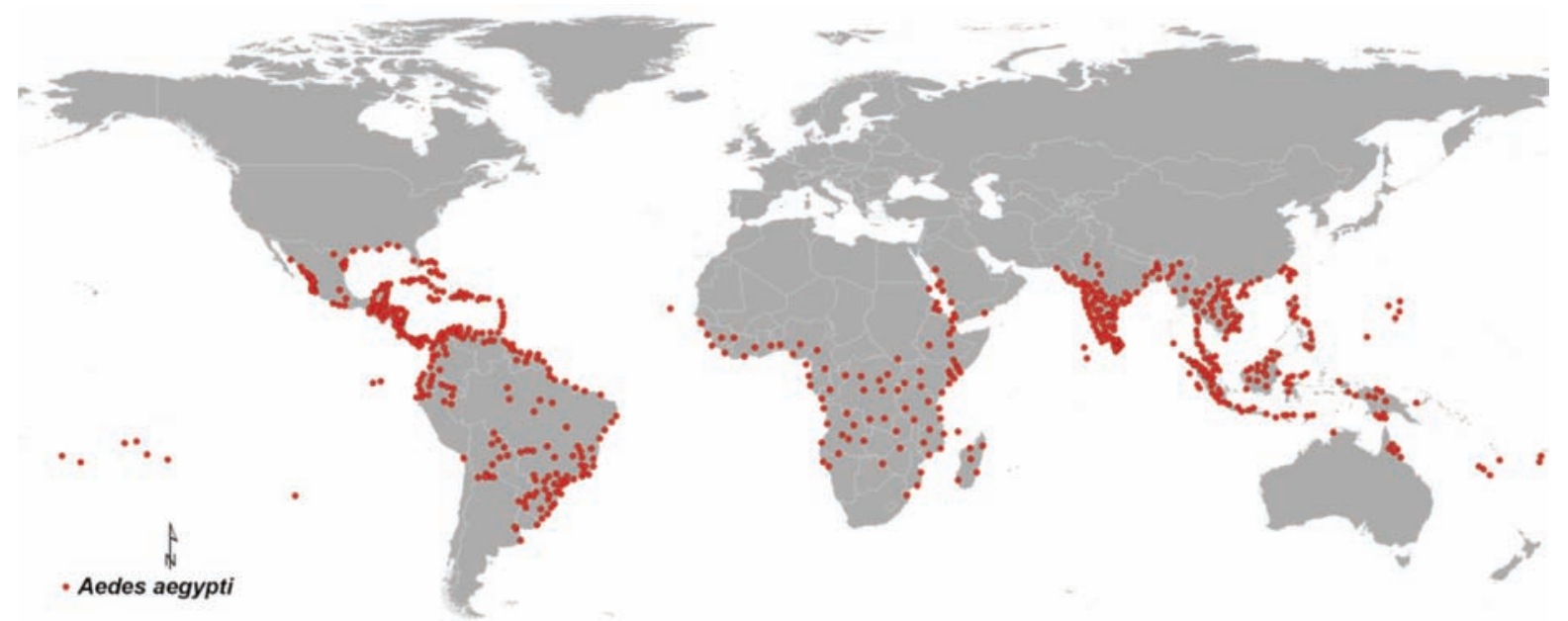

Fig. 1. Global distribution of the Aedes aegypti mosquito.

future climatic data available in the CLIMEX software, we developed models of the potential distribution of A. aegypti under current and two future climate scenarios 2030 and 2070.

\section{Climate data and climate change scenarios}

We used the CliMond 10' gridded climate data (http://www.hearne.com.au/Software/CLIMEX/Editio ns\#version_CLIMEX 3.0.2) to model the potential distribution of A. aegypti. To present the historical climate (averaging the period 1950-2000) and the projected climate in 2030 and 2070, we used average minimum and maximum monthly temperatures $\left(\mathrm{T}_{\min }\right.$ and $\mathrm{T}_{\max }$, respectively), average monthly precipitation $\left(\mathrm{P}_{\text {total }}\right)$ and the relative humidity at 09:00 $\mathrm{h}\left(\mathrm{RH}_{9: 00}\right)$ and 15:00 $\mathrm{h}\left(\mathrm{RH}_{15: 00}\right)$. The potential distribution was based on two different GCMs, CS and MR, available as part of the CliMond datasets.

The MR model predicts the temperature will increase roughly $4.31{ }^{\circ} \mathrm{C}$, while the CS model predicts a rise of $2.11^{\circ} \mathrm{C}$ by 2100 . There are also differences in rainfall patterns for the CS and MR models. For example, the CS model predicts a $14 \%$ decrease in future mean annual rainfall, whereas the MR model predicts a $1 \%$ decrease. We selected these two models out of 23 GCMs in the CliMond datasets because of (i) the temperature, precipitation, MSL pressure, and specific humidity variables required for CLIMEX were available for these two GCMs; (ii) the models have relatively small horizontal grid spacing; and (iii) they performed well compared to other GCMs in representing basic aspects of observed climate at a regional scale, according to Taylor et al. (2012) and Kriticos et al. (2011).
These two GCMs were run with the two different emission scenarios, A1B and A2, presented in the special report on emissions scenarios (SRES) issued by IPCC (IPCC, 2000, 2007; Gordon et al., 2002) and used to make projections of possible future climate changes. There are many different scenarios, each making different assumptions for future greenhouse gas pollution, land-use and other driving forces. The A1B scenario describes a balance between the use of fossil and non-fossil resources, while the A2 SRES scenario describes a varied world with high population growth, slow economic development and technological change (Taylor et al., 2012). We selected the A1B and A2 to typify two possible scenarios.

\section{Fitting the CLIMEX parameters}

In the present study, we used A. aegypti distribution data (and also dengue data, where there was a lack of information on A. aegypti), temperature and humidity as parameters together with cold and dry stresses because we felt these variables would approximate the potential distribution of the mosquito. All the parameters were fitted to known and suitable distributions of A. aegypti. Each parameter was adjusted iteratively to satisfy the agreement of the Aedes distribution, and the fitted parameters were checked to ensure that they were reasonable. Model validation was conducted using the distribution data from the Caribbean area, the southern and eastern coast of Brazil, western India as well as Bangladesh and the countries surrounding the South China Sea.

Many studies suggest that the Aedes mosquitoes are critically dependent on temperature, and that an increase within the span between a lower range of 14- 
$18{ }^{\circ} \mathrm{C}$ and an upper one of $35-40{ }^{\circ} \mathrm{C}$ can lead to higher transmission of dengue (Wallis, 2005). In Saudi Arabia, Khormi et al. (2011) found that the minimum temperature range of $18-25^{\circ} \mathrm{C}$ is suitable for mosquito survival and the survival rate increases at higher temperatures up to $38^{\circ} \mathrm{C}$. Conner (1924) as well as Wayne and Graham (1968) found that A. aegypti is most active at temperatures between $15^{\circ} \mathrm{C}$ and $30^{\circ} \mathrm{C}$, while other field and laboratory observations found survival rates from about $18{ }^{\circ} \mathrm{C}$ to $\leq 38{ }^{\circ} \mathrm{C}$, based on daily or monthly minimum and maximum temperatures (Macfie, 1920; Bliss and Gill, 1933; Christopher, 1960). Therefore, we set the limiting low temperature (DV0) at $18{ }^{\circ} \mathrm{C}$, the lower optimal temperature (DV1) at $25^{\circ} \mathrm{C}$, the upper optimal temperature (DV2) at $32^{\circ} \mathrm{C}$ and the limiting high temperature (DV3) at $38^{\circ} \mathrm{C}$. These settings provided the best fit to the observed distribution of A. aegypti.

The lowest limiting moisture (SM0) was set at 0 because it represents the permanent wilting point, and this number provided a good fit to the observed distribution of A. aegypti in drought areas such Saudi Arabia, Somalia, and some parts of South America. The lower (SM1) and upper (SM2) optimum moisture and the highest limiting moisture were set at 0.2, 0.5, and 4.0, respectively, to concur with improved species growth in the Pacific and Caribbean islands, Southeast Asia, and some countries in West Africa. Additionally, these values provided an appropriate fit to the observed distributions.

The heat stress parameter (TTHS) was set at $38^{\circ} \mathrm{C}$ because it is reported that in some countries such as Saudi Arabia and Somalia, A. aegypti is able to survive up to this temperature (Gubler and Clark, 1995; Khormi et al., 2011). The heat stress accumulation rate (THHS) was set at 0.9 week $^{-1}$ allowing A. aegypti to persist along western and south-western part of Saudi Arabia and eastern Somalia. The dry stress parameter was set at 0.001 for the dry stress threshold (SMDS) and -0.001 week $^{-1}$ for the dry stress rate (HDS), because these adjusted values provided an appropriate fit to the observed distributions.

\section{Geographical information systems (GIS)}

For more efficient visualization of the potential and future distributions around the world, we transferred the EI results to a GIS using ArcMap version 10 (ESRI; Redlands, USA). The given EI point features were converted to a raster surface, since rasters are effective in identifying where favourable climate areas are concentrated by highlighting areas based on the EI values from the CLIMEX analysis.

\section{Results}

The historical global climate model illustrates the known distribution of A. aegypti within in the tropical and subtropical areas (Fig. 2). A comparison with Fig. 1 shows that the present global distribution of Aedes is consistent with the EI values resulting from the CLIMEX model, i.e. Brazil, large areas of Central America, the Caribbean islands, parts of the western and eastern coasts of Africa, the Pacific island groups, the northeast coast of Australia, western India and Bangladesh. More than $80 \%$ of the areas where the

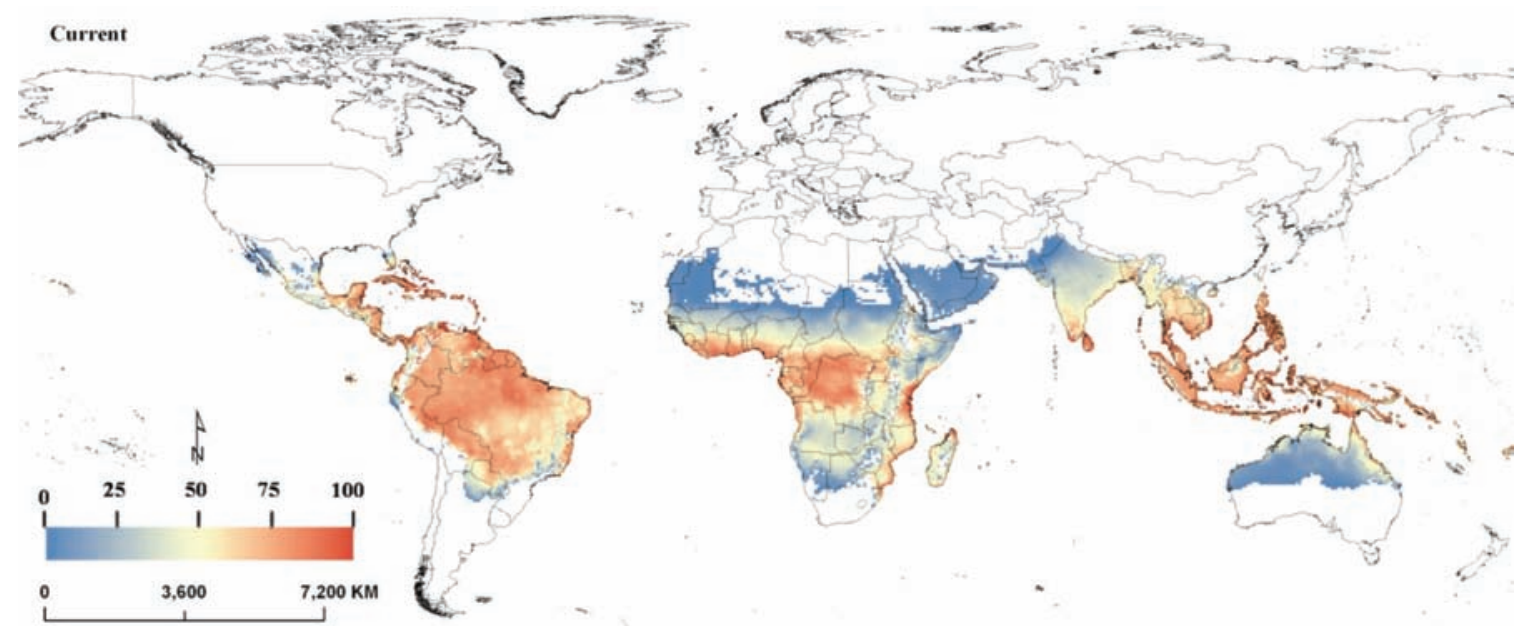

Fig. 2. Suitability for A. aegypti based on the eco-climatic index (EI) and CLIMEX modelling of the reference climate (temperature average for the period 1950-2000).

White = areas unfavourable for the Aedes mosquito $(\mathrm{EI}=0)$; blue = marginally suitable areas $(\mathrm{EI}=1-10)$; blue/yellow = favourable areas $(\mathrm{EI}=10-20)$; yellow/red $=$ very favourable areas $(\mathrm{EI}>30)$. 
mosquito has been observed fall within climate conditions deemed favourable or very favourable, indicating a strong concordance between actual records and the predicated conditions.

For the future climate conditions (2030 and 2070), we observed a contraction in the strongly positive climate areas for A. aegypti worldwide with both emission models (Figs. 3-6), a trend that was particularly strong in the 2070 scenario. In South America, especially in Brazil, Colombia, Guyana, Paraguay and Venezuela, the areas with a currently very favourable climate became substantially reduced and a similar trend was also seen on the eastern coast of India, Bangladesh, Myanmar, Malaysia, Singapore Thailand, Cambodia and Vietnam. By 2030, reductions of the favourable and the very favourable climate areas for the mosquito are seen in most of these countries (Figs. 3 and 5), and this contraction becomes more obvious in the 2070 projection (Figs. 4 and 6). Counter-intuitively, the warming projected for future climate sce- narios is likely to lead to a substantial reduction of areas currently suitable for A. aegypti. No particular divergences were noted between the two GCM results, but a small difference between the CS and MR models was observed in Bangladesh, Myanmar, Thailand, Vietnam and Cambodia. While these areas ranged from very favourable to favourable according to the CS model, they varied from very highly favourable to very favourable with the MR model, a trend that was enforced in the 2070 scenario.

In most of the Pacific and Caribbean islands and also Sri Lanka, suitable Aedes climate areas are projected to continue under both GCMs and both emission scenarios tested. In Africa, for example, the Democratic Republic of the Congo, the Congo Republic, Gabon, the southern coast of Benin, Nigeria, Togo, Ghana, and Côte d'Ivoire are likely to continue as very highly favourable in 2030 but shift slightly downwards in 2070. In northern Africa, marginal to favourable ranges climate for $A$. aegypti were
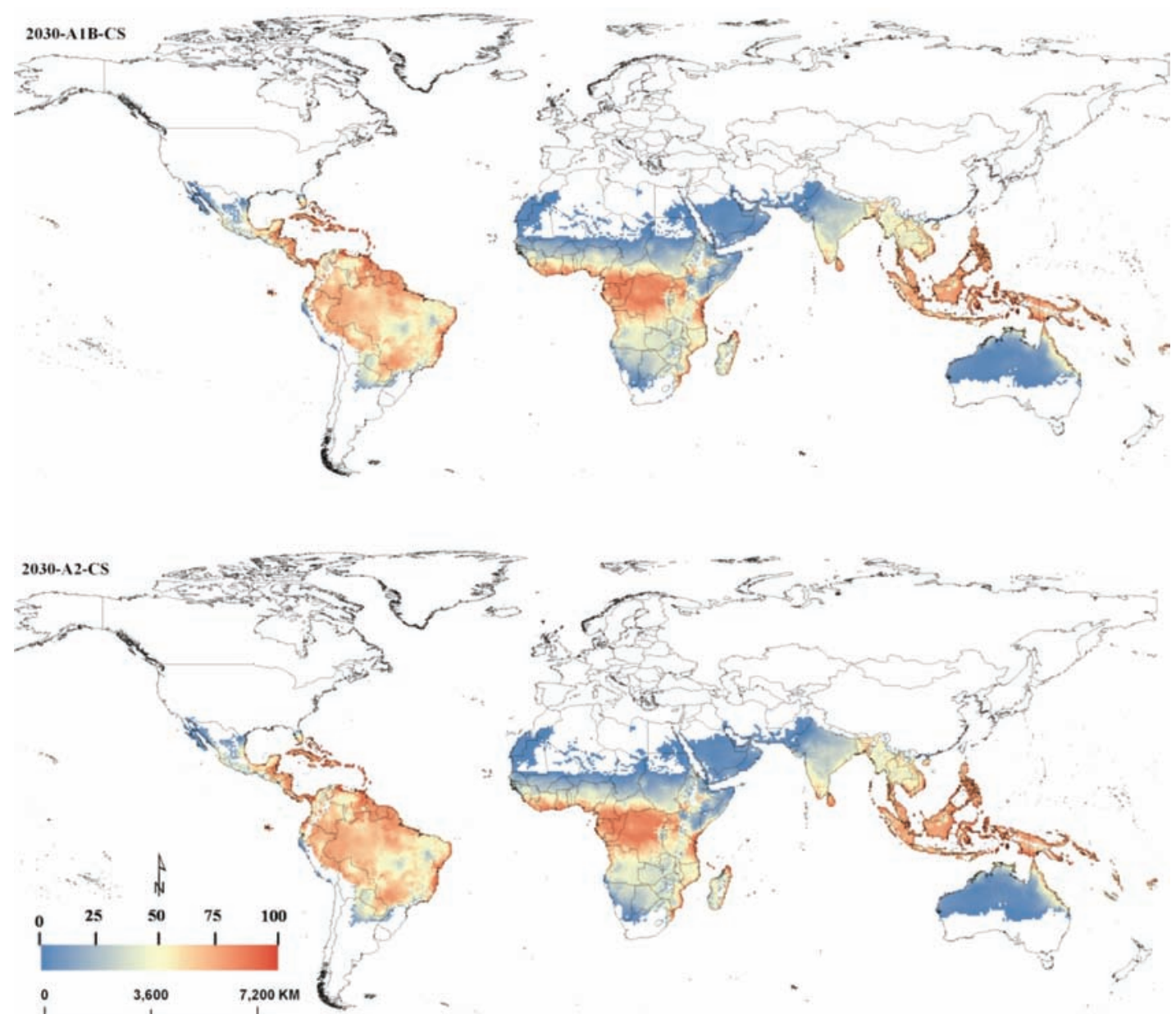

Fig. 3. Estimated suitability for A. aegypti in 2030 based on the eco-climatic index (EI) and CLIMEX under CSIRO-Mk3.0 GCM running the $\mathrm{A} 1 \mathrm{~B}$ and $\mathrm{A} 2$ emission scenarios).

White $=$ areas unfavourable for the Aedes mosquito $(E I=0)$; blue = marginally suitable areas $(E I=1-10)$; blue/yellow = favourable areas $(\mathrm{EI}=10-20)$; yellow/red $=$ very favourable areas $(\mathrm{EI}>30)$. 

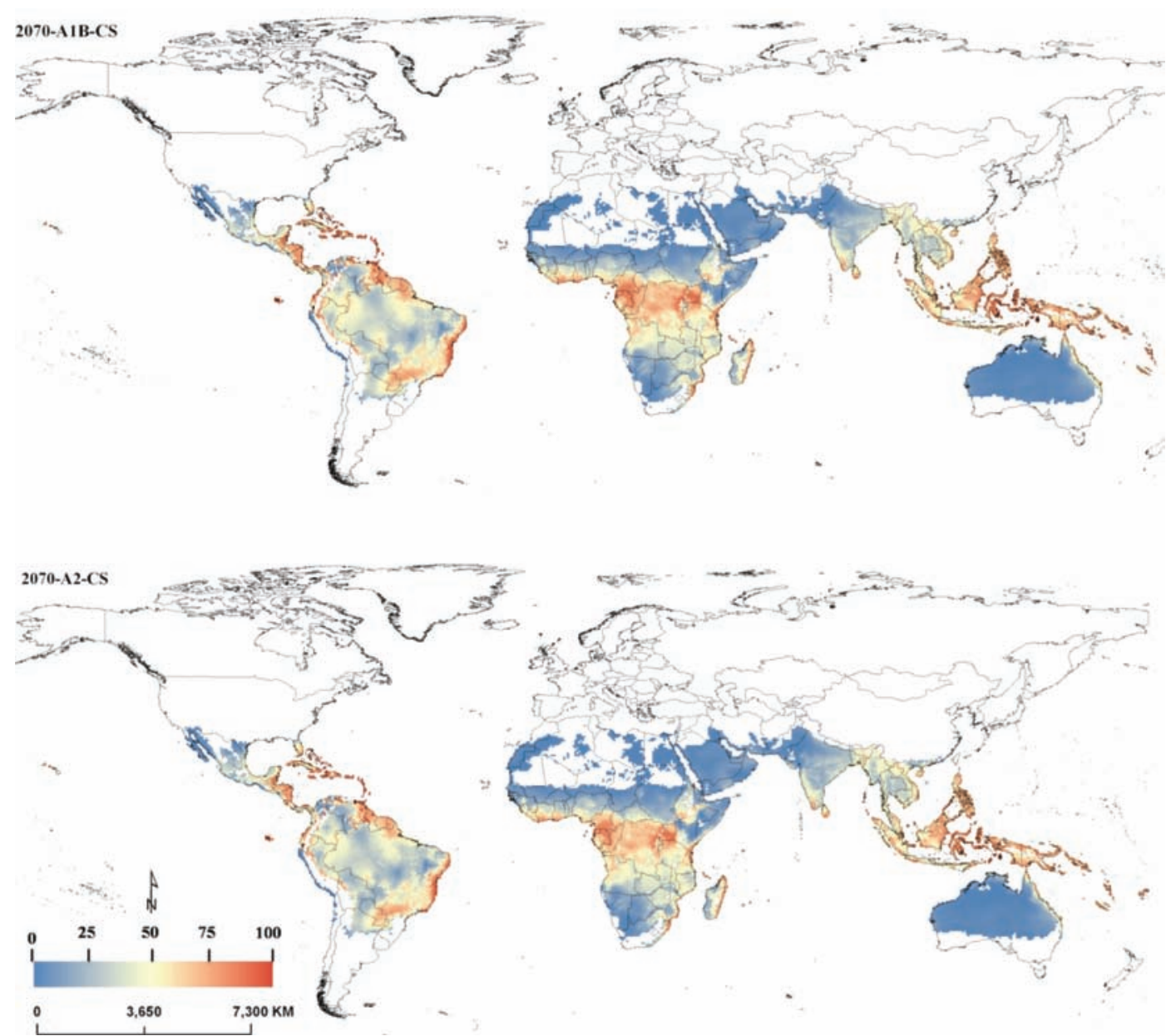

Fig. 4. Estimated suitability for A. aegypti in 2070 based on the eco-climatic index (EI) and CLIMEX under CSIRO-Mk3.0 GCM running the $\mathrm{A} 1 \mathrm{~B}$ and $\mathrm{A} 2$ emission scenarios.

White $=$ areas unfavourable for the Aedes mosquito $(\mathrm{EI}=0)$; blue $=$ marginally suitable areas $(\mathrm{EI}=1-10)$; blue/yellow $=$ favourable areas $(\mathrm{EI}=10-20)$; yellow/red $=$ very favourable areas $(\mathrm{EI}>30)$.

seen along the west coasts of Mauritania and Morocco and expand in Libya and Egypt, especially in 2070. The same trend was observed in southern Iran, the Arabian Peninsula and Australia.

\section{Discussion}

Climate is the main determinant of the distribution of plants and poikilothermal animals (Andrewartha and Birch, 1954; Sutherst et al., 2007), so research accounting for a species' response to the climate based on phenological observations or the geographical range should be useful with respect to its spatio-temporal distribution in a scenario that includes environmental variation. Since the CLIMEX software is based on the formation of an eco-physiological model that assumes that a favourable climate enables the species to flourish, while unfavourable conditions would result in its decline, we felt that it could be be effective in estimation of the potential of A. aegypti under cur- rent and future climate changes.

Assessment of the health impacts due to climate change is clearly important, and site-specific assessments would best account for both global dynamics and local conditions affecting dengue transmission, especially if large-scale data could be combined with small-scale, local investigations. However, this would require analysis accounting both for spatial and temporal levels, the latter for the long term (Patz et al., 1996). An important adjunct to managing a complicated disease system and traditional methods of investigation can be aided and represented by computer simulation modelling. In particular, it is useful in evaluating long-term climate variability, for which prospective studies lack feasibility and historical studies lack similarity (Marten et al., 1995; Patz et al., 1998).

This study confirms the influence of temperature on dengue and its vector as well as the sensitivity of transmission to temperature change. In Honduras, for 

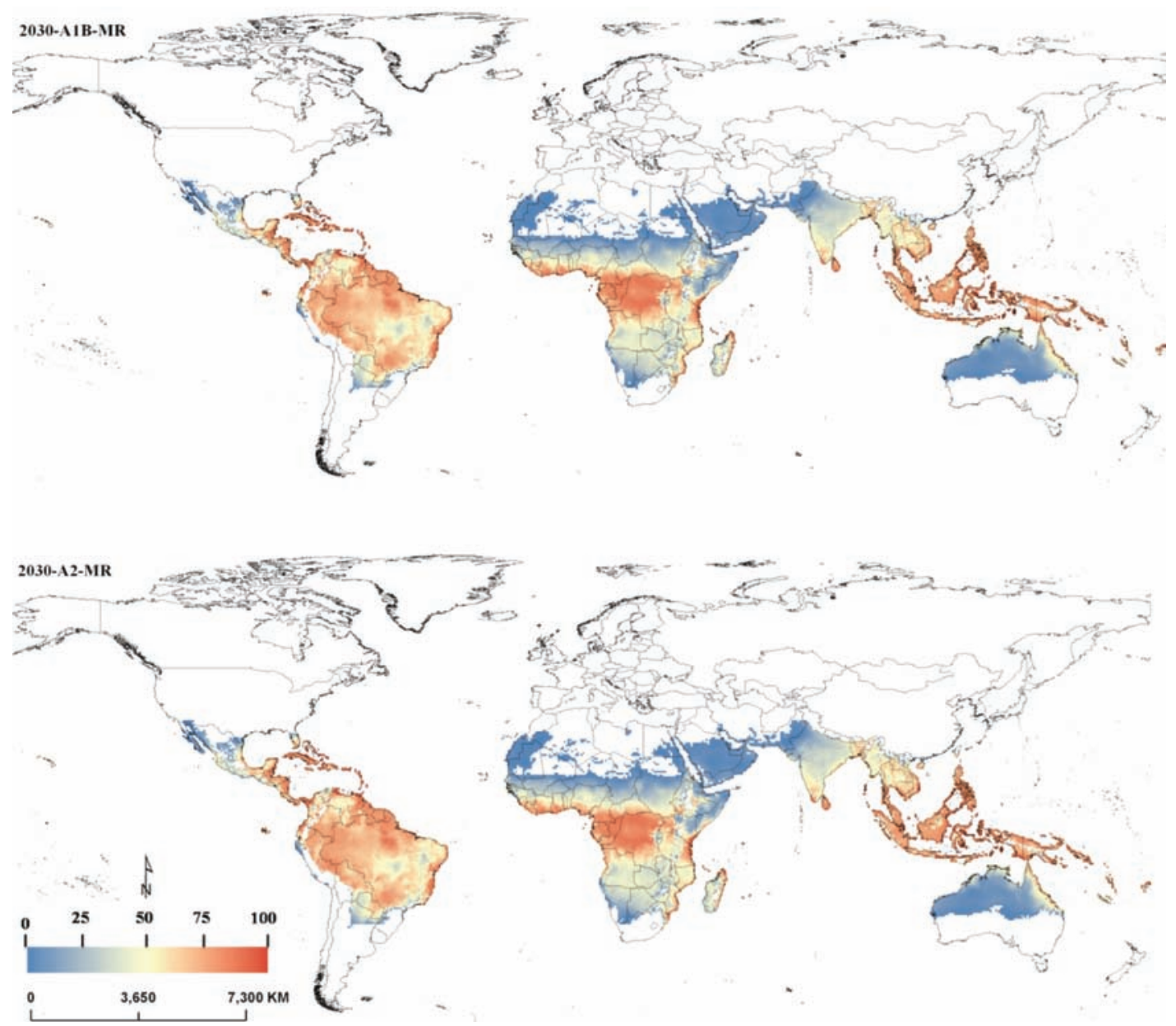

Fig. 5. Estimated suitability for A. aegypti in 2030 based on the eco-climatic index (EI) and CLIMEX under MIROC-H GCM running the $\mathrm{A} 1 \mathrm{~B}$ and $\mathrm{A} 2$ emission scenarios.

White $=$ areas unfavourable for the Aedes mosquito $(\mathrm{EI}=0)$; blue $=$ marginally suitable areas $(\mathrm{EI}=1-10)$; blue/yellow $=$ favourable areas $(\mathrm{EI}=10-20)$; yellow/red $=$ very favourable areas $(\mathrm{EI}>30)$.

example, an epidemic dengue transmission did not occur in Tegucigalpa, where the average temperature is $4{ }^{\circ} \mathrm{C}$ lower than in the coastal lowlands, where dengue commonly transmission occurs (Patz et al., 1998). In Mexico, dengue and its vector were recorded at the surprising altitude of $1,700 \mathrm{~m}$ above the MSL during the unusually warm summer of 1988 (HerreraBasto et al., 1992), while Koopman et al. (1991) reported a fourfold increase observed between $17^{\circ} \mathrm{C}$ and $30^{\circ} \mathrm{C}$ of the median temperature during the rainy season. Indeed, temperature per se might not be the single most important predictor of dengue prevalence since Patz et al. (1998) also noted dengue outbreaks taking place not during the hottest period of the year but during the rainy season. Still, it remains the key determining factor as we have seen in this study.

Although cold stress, on the other hand, appears to be the main factor limiting mosquito distribution since freezing temperatures kill the eggs, larvae, and adults of A. aegypti (Chandler, 1945), dry stress prevents the establishment of the mosquito in the drier southern parts of South America, inland Australia, and northern Saudi Arabia (Chandler, 1945; Khormi et al., 2011). Within the marginal areas currently identified in much of Saudi Arabia and inland Australia, Aedes would be patchily distributed and restricted to favourable microhabitats. Thus, in these areas, it would pose a limited threat characterised by slow dispersal.

Part of eastern and central Africa and parts of West Africa as well as northern Australia are projected to have favourable to highly favourable climatic conditions for A. aegypti, greatly exceeding its current known distribution there. This could, however, be due to lack of reliable records from these regions. Other non-climatic factors such as lack of dispersal opportunities could also inhibit A. aegypti from spreading in these regions (Gubler, 1995).

The results identified here point at new areas of the world that may be at risk of A. aegypti due to changes 

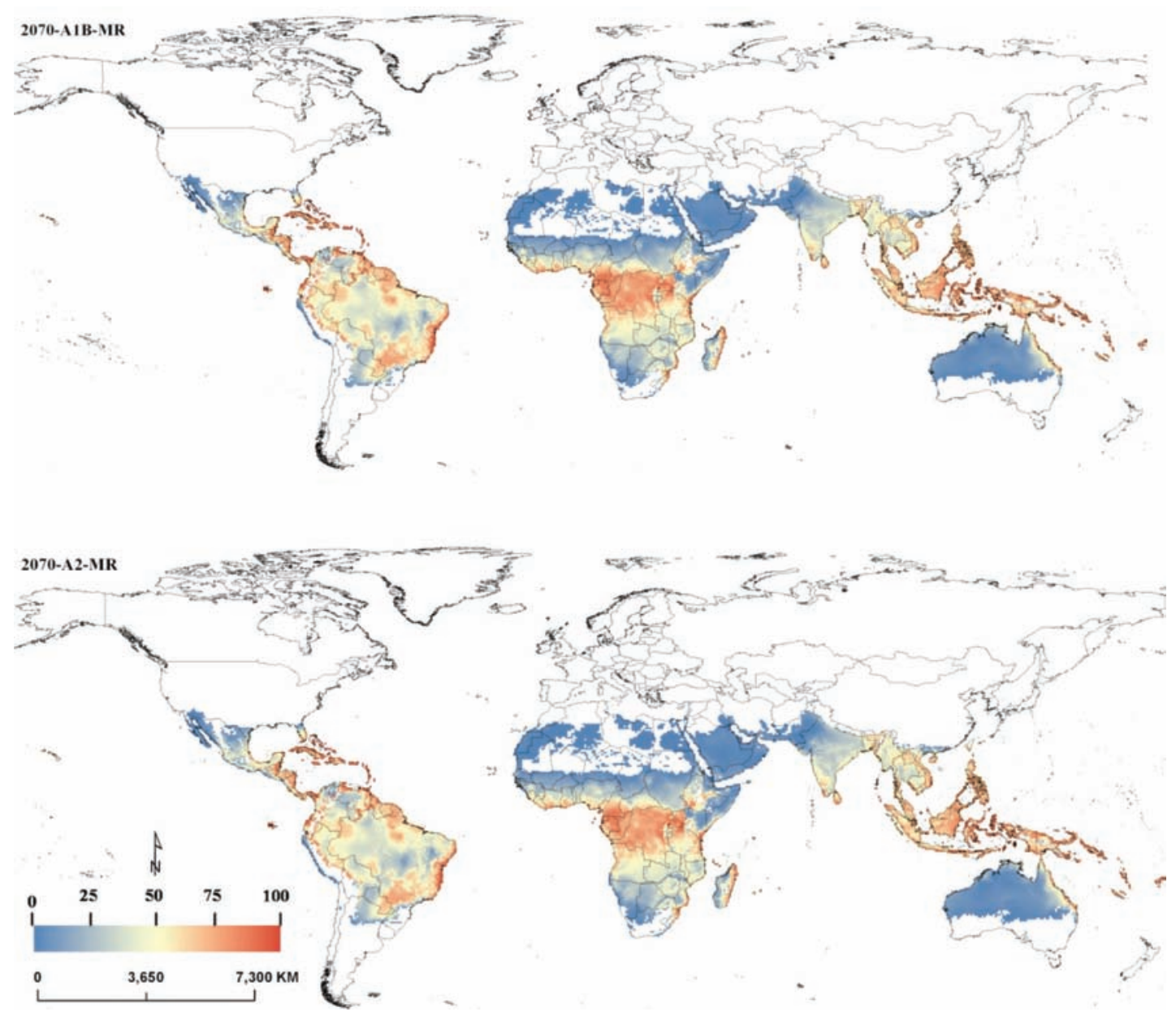

Fig. 6. Estimated suitability for A. aegypti in 2070 based on the eco-climatic index (EI) and CLIMEX under MIROC-H GCM running the $\mathrm{A} 1 \mathrm{~B}$ and $\mathrm{A} 2$ emission scenarios.

White $=$ areas unfavourable for the Aedes mosquito $(\mathrm{EI}=0)$; blue $=$ marginally suitable areas $(\mathrm{EI}=1-10)$; blue/yellow $=$ favourable areas $(\mathrm{EI}=10-20)$; yellow/red $=$ very favourable areas $(\mathrm{EI}>30)$.

of the climate, and warrants strategic control measures to prevent the spread of this species of mosquito. Although an overall reduction in the potential distribution is projected in Central and South America, Africa, and Asia under the future climate scenarios examined, the potential for range expansion in North Africa, Australia, the Arabian Peninsula, Iran and Pakistan was identified. In South Africa and south China, A. aegypti could expand further inland into new areas in the future.

Assessing and managing risks from mosquitoes depend to a large extent on projections of habitat suitability so that threat levels can be assessed. The response of $A$. aegypti to changes in climate must form an integral part of such assessments. Particularly, areas that are currently at risk and that will continue to be at risk from the mosquito in the future were identified in this study. These areas would need monitoring, particularly in hotspots in northeast Australia, Central America, North America and the middle of South
America, Caribbean and Pacific islands, areas characterised by high populations. A. aegypti may also expand into areas that are currently too hot for it to survive, and this can be seen in improved suitability in Arabian Peninsula countries and some North African countries. Areas of Iran and Pakistan have also been identified as becoming climatically suitable for A. aegypti in the future.

Surprisingly, the overall result of the modelling reported here indicates an overall contraction in the climatically suitable area for Aedes in the future (Figs. 2-6). Some of this reduced potential range for A. aegypti covers important hotspots of the world (e.g. countries in the South China Sea, Brazil, eastern India and Sri Lanka). The situation is not straightforward but rather complicated as some areas will see an upsurge in transmission, while others are likely to see a decline. Therefore, additional etiologic factors not addressed at this level of integrated modelling must ultimately be incorporated to determine human risk to 
dengue fever and its vector. To the current re-emergence of dengue and its vector in certain places may be due to urbanization, population density, poverty, inadequate mosquito control, absence of water systems, international travel or migration, all believed to be contributing factors (Gubler and Clark, 1995). Future integrated models should attempt to account for these site-specific factors as well (Lifson, 1996) while climate conditions play a part in the epidemic spread and geographical distribution of dengue (Reiter, 1988; Reiter and Gubler, 1997).

Models such as the ones produced in this study can be useful tools in public awareness campaigns to enlist the help of health authorities in managing existing infestations and preventing further abundance. Our results can be used in decision-making processes by health managers in prioritizing areas for eradication and in determining areas where containment would be cost-effective. Health agencies in endemic and potentially endemic countries should be aware of this potential threat and monitor areas that have been identified in this study for early signs of mosquito populations becoming a risk. Simple and low-cost strategies such as monitoring alerts, identifying distribution areas at risk, low-cost surveillance systems, and hygiene efforts to prevent the spread of mosquitoes to new areas may be a worthwhile investment by health agencies in these countries. Climatic suitability for A. aegypti may increase, even leading to range contraction, in places where conditions become warm and wet (e.g. inland Australia).

The approach pioneered here could contribute to informed choices about allocating resources for mosquito control by highlighting areas where climate suitability is expected to decrease in the future. Other factors such as the source of infection, the mosquito and susceptible human populations, also need to be present for a dengue epidemic to happen with the suitable climate. Where and when dengue occurs in the future will then depend on various economic, social and environmental factors (Khormi and Kumar, 2011).

\section{Conclusion}

The climate models for the dengue vector presented here are useful for management purposes, particularly with regard to future climate change. They can be adapted for making decisions regarding allocating resources for dengue risk towards areas where risk infection remains and away from areas where climatic suitability is likely to decrease in the future climate. These models would facilitate prioritizing dengue management initiatives in current risk areas and those with continuing risk in the future.

Issues such as excessive resource consumption in rich countries, an increase in social inequality and population increases in poor countries should be taken into account because addressing them would help reducing the mosquito risk and dengue prevalence in the future.

The study models used in this study can help reducing the challenges faced by national health services when improving early detection of favourable areas for the mosquito and dengue transmission. The strategy presented here should be supported by the implementation of a sufficiently effective surveillance system for viral diseases on a regional basis.

\section{Acknowledgement}

Authors thank KACST GIS Technology Innovation Centre for supporting this project under the project number GISTIC-13-04.

\section{References}

Andrewartha HG, Birch LC, 1954. The distribution and abundance of animals. Chicago: University of Chicago Press, 782 pp.

Bliss AR, Gill JM, 1933. The effects of freezing on the larvae of Aedes aegypti. Am J Trop Med Hyg 13, 583-588.

Center for International Earth Science Information Network (CIESIN). Available at: http://www.ciesin.org/docs/001613/map15.gif (accessed on July 2012).

Centers for Disease Control and Prevention, 2012. DengueMap. Available at: http://www.healthmap.org/dengue/index.php (accessed on July 2012).

Chandler AC, 1945. Factors influencing the uneven distribution of Aedes aegypti in Texas cities. Am J Trop Med 25, 145-149. Chejara VK, Kriticos DJ, Kristiansen P, Sindel BM, Whalley RDB, Nadolny C, 2010. The current and future potential geographical distribution of Hyparrhenia hirta. Weed Res 50, 174-184.

Christophers SR, 1960. Aedes aegypti (L.) the yellow fever mosquito. Its life history, bionomics and structure. Cambridge: Cambridge University Press.

Connor ME, 1924. Suggestions for developing a campaign to control yellow fever. Am J Trop Med 4, 277-307.

Gordon HB, Rotstayn LD, McGregor JL, Dix MR, Kowalczyk EA, O'Farrell SP, Waterman LJ, Hirst AC, Wilson SG, Collier $\mathrm{M}$ et al., 2002. The CSIRO Mk3 climate system model, CSIRO atmospheric research technical paper No. 60, CSIRO Atmospheric Research, Aspendale.

Gratz NG, 2004. Critical review of the vector status of Aedes albopictus. Med Vet Entomol 18, 215-227. 
Gubler DJ, 1998a. Resurgent vector-borne diseases as a global health problem. Emerg Infect Dis 4, 442-450.

Gubler DJ, 1998b. Dengue and dengue hemorrhagic fever. Clin Microbiol Rev 11, 480-496.

Gubler DJ, 2002. The global emergence/resurgence of arboviral diseases as public health problems. Arch Med Res 33, 330342 .

Gubler DJ, 2003. Aedes albopictus in Africa. Lancet 3, 751752.

Gubler DJ, 2004. The changing epidemiology of yellow fever and dengue 1900 to 2003: full circle? Comp Immunol Microbiol Infect Dis 27, 319-330.

Gubler DJ, Clark GG, 1995. Dengue/dengue hemorrhagic fever: the emergence of a global health problem. Emerg Infect Dis 1, 55-57.

Gubler DJ, Kuno G, 1997. Dengue and dengue hemorrhagic fever. CAB International, $478 \mathrm{pp}$.

Gubler DJ, Trent DW, 1994. Emergence of epidemic dengue/dengue hemorrhagic fever as a public health problem in the Americas. Infect Agents Dis 2, 383-393.

Haines A, Kovats RS, Campbell-Lendrum D, Corvalan C, 2006. Climate change and human health: impacts, vulnerability and public health. Public Health 120, 585-596.

Hales S, de Wet N, Maindonald J, Woodward A, 2002. Potential effect of population and climate changes on global distribution of dengue fever: an empirical model. Lancet 360, 830-834.

Hales S, Weinstein P, Woodward A, 1996. Dengue fever epidemics in the South Pacific: driven by El Niño southern oscillation? Lancet 348, 1664-1665.

Herrera-Basto E, Prevots DR, Zarate ML, Silva JL, SepulvedaAmore J, 1992. First reported outbreak of classical dengue fever at 1700 meters above sea level in Guerrero state, Mexico, June 1988. Am J Trop Med Hyg 46, 649-635.

Hopp MJ, Foley JA, 2001. Global-scale relationships between climate and the dengue fever vector, Aedes aegypti. Climatic Change 48, 441-463.

IPCC, 2000. Special report on emissions scenarios: a special report of working group III of the Intergovernmental Panel on Climate Change. Cambridge, Cambridge University Press.

IPCC, 2007. Climate change 2007: the physical science basis. Contribution of working group I to the fourth assessment report of the Intergovernmental Panel on Climate Change. Cambridge, Cambridge University Press.

Jackson EK, 1995. Climate change and global infectious disease threats. Med J Aust 163, 570-574.

Jetten TH, Focks DA, 1997. Potential changes in the distribution of dengue transmission under climate warming. Am J Trop Med Hyg 57, 285-297.

Johansson MA, Dominici F, Glass GE, 2009. Local and global effects of climate on dengue transmission in Puerto Rico. PLoS Negl Trop Dis 3, e382.
Khormi HM, Kumar L, 2011. Examples of using spatial information technologies for mapping and modelling mosquitoborne diseases based on environmental, climatic, socioeconomic factors and different spatial statistics, temporal risk indices and spatial analysis: a review. J Food Agr Environ 9, 41-49.

Khormi HM, Kumar L, Elzahrany R, 2011. Describing and analyzing the association between meteorological variables and adult Aedes aegypti mosquitoes. J Food Agr Environ 9, 954959.

Koopman JS, Prevots DR, Vaca Marin MA, Gomez Dantes H, Zarate Aquino ML, Longini Jr IM, Sepulveda Amor J, 1991. Determinants and predictors of dengue infection in Mexico. Am J Epidemiol 133, 1168-1178.

Kriticos DJ, Webber BL, Leriche A, Ota N, Macadam I, Bathols J, Scott J, 2011. CliMond: global high-resolution historical and future scenario climate surfaces for bioclimatic modelling. Method Ecol Evol, 53-64.

Kriticos DJ, Yonow T, McFadyen RE, 2005. The potential distribution of Chromolaena odorata (Siam weed) in relation to climate. Weed Res 45, 246-254.

Lifson AR, 1996. Mosquitoes, models, and dengue. Lancet 347, 1201-1202.

Lounibos LP, 2002. Invasions by insect vectors of human disease. Annu Rev Entomol 47, 233-266.

Macfie JWS, 1920. Heat and Stegomyia fasciata, short exposures to raised temperatures. Ann Trop Med Parasitol 14, 7382.

Martens WJM, Jetten TH, Focks DA, 1997. Sensitivity of malaria, schistosomiasis, and dengue to global warming. Climate Change 35, 145-156.

Martens WJM, Jetten TH, Rotmans J, Niessen LW, 1995. Climate change and vector-borne diseases. Global Environ Change 5, 195-209.

Medlock JM, Snow KR, Leach S, 2005. Potential transmission of West Nile virus in the British Isles: an ecological review of candidate mosquito bridge vectors. Med Vet Entomol 19, 221.

Moore CG, 1999. Aedes albopictus in the United States: current status and prospects for further spread. J Am Mosq Control Assoc 15, 221-227.

Moore CG, Mitchell CJ, 1997. Aedes albopictus in the United States: ten-year presence and public health implications. Emerg Infect Dis 3, 329-334.

Patz JA, Epstein PR, Burke TA, Balbus JM, 1996. Global climate change and emerging infectious disease. JAMA 275, 217 223.

Patz JA, Martens WJM, Focks DA, Jetten TH, 1998. Dengue fever epidemic potential as projected by general circulation models of global climate change. Environ Health Perspect 106, 147-153.

Pinheiro FP, Chuit R, 1998. Emergence of dengue hemorrhagic 
fever in the Americas. Infect Med 15, 244-251.

Poutsma J, Loomans AJM, Aukema B, Heijerman T, 2008. Predicting the potential geographical distribution of the harlequin ladybird, Harmonia axyridis, using the CLIMEX model. BioControl 53, 103-125.

Reiter P, 1988. Weather, vector biology, and arboviral recrudescence. In: The Arboviruses: epidemiology and ecology, Vol. 1, FLCRC Press, 245-255 pp.

Reiter P, 2001. Climate change and mosquito-borne disease. Environ Health Perspect 109, 141-161.

Reiter P, Gubler DJ, 1997. Surveillance and control of urban dengue vectors. In: Dengue and dengue hemorrhagic fever. Gubler DJ, Kuno G (eds). CAB International, 425-462 pp.

Rogers DJ, Wilson AJ, Hay SI, Graham AJ, 2006. The global distribution of yellow fever and dengue. Adv Parasitol 62, 181-220.

Rueda LM, Patel KJ, Axtell RC, Stinner RE, 1990. Temperature-dependent development and survival rates of Culex quinquefasciatus and Aedes aegypti (Diptera: Culicidae). J Med Entomol 27, 892-898.

Suarez MF, Nelson MJ, 1981. Registro de altitud del Aedes aegypti en Colombia. Biomedica 1, 225.
Sutherst RW, Bourne AS, 2009. Modelling non-equilibrium distributions of invasive species: a tale of two modelling paradigms. Biol Invasions 11, 1231-1237.

Sutherst RW, Maywald G, Kriticos DJ, 2007. CLIMEX version 3. User's guide, Hearne Scientific Software Pty Ltd., 131 pp.

Taylor S, Kumar L, Reid N, Kriticos DJ, 2012. Climate change and the potential distribution of an invasive shrub, Lantana camara (L.). PLoS One 7, e35565.

Wallis RC, 2005. A GIS model for predicting potential "high risk" areas of West Nile virus by identifying ideal mosquito breeding habitats. MSc thesis, Environmental Science, Mississippi State University.

Wayne AR, Graham CL, 1968. The effect of temperature and relative humidity on the flight performance of female Aedes aegypti. J Insect Physiol, 14, 1251-1257.

Wharton TN, Kriticos DJ, 2004. The fundamental and realized niche of the Monterey Pine aphid, Essigella californica (Essig) (Hemiptera: Aphididae): implications for managing softwood plantations in Australia. Divers Distrib 10, 253-262.

WHO, 2013. Dengue and severe dengue. Geneva: World Health Organization. Available at: http://www.who.int/mediacentre/ factsheets/fs117/en/ (accessed on March 2014). 